\section{Views of child psychiatrists on physical contact}

\section{with patients}

\author{
AILEEN BLOWER, RODDY LANDER, ANNA CR AWFORD, RUTH ELLIOT, \\ CLARE MCNULTY, CHRISTOPHER HOLMES, PAVAN SRIREDDY, \\ MICHELLE MULCAHY and HELEN MINNIS
}

\begin{abstract}
Summary The appropriateness and therapeutic value of physical contact with children is under increasing scrutiny. We conducted a postal questionnaire and telephone survey of consultant child and adolescent psychiatrists within Great Britain to investigate attitudes of specialists towards physical contact with their patients in different clinical contexts. Here we report that psychiatrists tend to restrict physical contact to the minimum essential for patient comfort or safety. Decision-making about contact is primarily influenced by professional experience and training. This conservative approach to physical contact with patients has implications for clinical practice and requires to be better informed by evidence.
\end{abstract}

\section{Declaration of interest None.}

Funding detailed in Acknowledgements.

Good clinical decisions are key to ensuring the quality of patient care (Klein, 2005). Child psychiatrists frequently have to make difficult decisions about physical contact with their patients. Physical contact is important for children's growth and development (Feldman, 2004) and is the basis of various treatment approaches for developmental difficulties (Brody, 1992; Field, 1998). Guidelines are emerging for managing psychiatric problems, including aggressive behaviour, with interventions which include physical contact (Masters $e t$ al, 2002). However, the evidence base is weak and psychiatrists must rely on other influences when making decisions in this complex area. We investigated the views of child and adolescent psychiatrists in Great Britain toward physical contact with their patients.

\section{METHOD}

Eleven child and adolescent psychiatrists who were attending a national conference participated in focus group interviews which informed design of the following two-stage method.

Questionnaires were posted to all 435 consultant child and adolescent psychiatrists in Great Britain, who were identified using the Royal College of Psychiatrists' database. Two hundred and sixty-one questionnaires were returned, yielding a response rate of $60 \%$. Respondents were aged between 31 and 75 years (50th centile 45 years); $53 \%$ were female. (For reasons of data protection, demographics of the population are not available for comparison.) The questionnaire invited responses to a clinical vignette, which described a distressed child who seeks comfort and then runs towards a busy road. Respondents rated the appropriateness of various possible courses of action. Responses of subgroups of psychiatrists were compared using $\chi^{2}$ tests or McNemar's test for paired data. Data were analysed using the Statistical Package for the Social Sciences version 11, for Windows.

Respondents to the survey were asked to indicate whether they wished to further express their views in a telephone interview. Of the 261 respondents, 20 indicated that they would and half of these participated in a telephone interview 2 months later. Also, 84 child and adolescent psychiatrists were selected at random and contacted sequentially for a semi-structured telephone interview until no new themes emerged $(n=15)$.

Participants were asked to describe personal and professional factors which influence their views on physical contact with children in various therapeutic situations. Interviews were audiotaped and transcribed for analysis of content using an iterative method. Integrity of thematic analysis was cross-checked using three independent raters. Results of the analysis are summarised below, with raw data presented as supporting statements.

\section{RESULTS}

\section{Questionnaire responses}

Responses to clinical vignettes are summarised in Table 1. Female and younger respondents were more likely to minimise contact with children than their male or older colleagues $(P=0.037$ and 0.048 respectively). Those who suggested restraining the child themselves were also significantly more likely to ask someone else to restrain them $(P=0.02)$. There was no association between willingness to comfort and willingness to restrain the patient $(P=0.837)$. When asked about the importance of setting, 97 of 261 respondents $(37 \%)$ stated that they would be 'just as likely' to restrain the child on an in-patient unit.

\section{Responses to telephone interviews}

Factors influencing attitudes of psychiatrists towards physical contact are described below.

\section{Role of the psychiatrist}

Interviewees said that being a psychiatrist restricted their physical contact with patients, in comparison with parents, carers and other medical practitioners. Respondents said this professional boundary should be especially protected within inpatient settings. Respondents spoke of conflict between their role as a psychiatrist and their natural human response:

'I would use as little physical contact as I could . . consistent with maintaining a kind of human compassionate relationship with the child'.

\section{Attitudes of the child}

A younger child was considered more likely to seek out and benefit from physical contact. Approaches from adolescents generally made respondents feel more uncomfortable, for example because the contact initiated seemed to represent sexualised behaviour. Interviewees expressed particular reservations about physical contact with children who had experienced physical or sexual abuse. Psychiatrists said that they might resort to physical contact in exceptional situations in which the child was very ill or engaging in violent or dangerous behaviour. This conservative stance was questioned:

'Why does it take a life-threatening condition before some psychiatrists will consider touching a child? 


\section{Professional influences}

Training, education and professional experience were identified as the most powerful influences upon respondents' attitudes.

'We were very much taught that there should be no physical contact whatsoever'.

Psychiatrists reported their lack of specific training in physical restraint. Some respondents reported allegations of professional misconduct against themselves or colleagues. These experiences had a major impact upon clinical practice, including the development of policies prohibiting physical contact with young people.

\section{Personal experience}

Some psychiatrists identified ways in which their views might have been affected by their own upbringing or current family life, but these influences were secondary to professional influences.

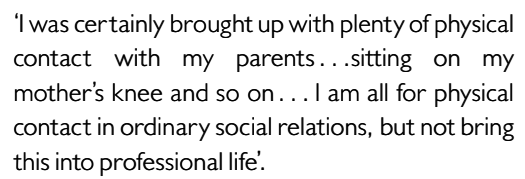
contact with my parents...sitting on my mother's knee and so on . . I I am all for physical contact in ordinary social relations, but not bring this into professional life'.

\section{Misinterpretation of physical contact}

Respondents stated that physical contact might be misinterpreted, especially sexually, with associated risks for the child and psychiatrist ('fraught... opening up a can of worms'). Many said that they would

\section{Ethical issues}

Psychiatrists raised the concern that physical contact might be confusing and potentially damaging to the child.

'What would the child make of somebody holding them in such an intimate way... and then walking away, not being part of their life?'

Difficulties in obtaining valid consent for physical contact were emphasised, as well as the importance of hearing the

AILEEN BLOWER, MRCPsych, RODDY LANDER, ANNA CRAWFORD, RUTH ELLIOT, CLARE McNULTY, CHRISTOPHER HOLMES, PAVAN SRIREDDY, MBChB, MICHELLE MULCAHY, MBChB, HELEN MINNIS, MRCPsych, PhD, Section of Psychological Medicine, University of Glasgow, Caledonia House, Royal Hospital for Sick Children, Glasgow, UK

Correspondence: Dr Helen Minnis, Section of Psychological Medicine, University of Glasgow, Caledonia House, Royal Hospital for Sick Children, Glasgow G3 8SJ, UK. Tel: +44 (0) I4I 201 9239; fax: +44 (I) I4I 2010620 ; e-mail: h.minnis@clinmed.gla.ac.uk

(First received 27 January 2005, final revision 29 July 2005, accepted 27 October 2005) insist on the presence of a chaperone.

child's point of view - 'respecting the child's wishes is a paramount principle in therapeutic contact'.

\section{DISCUSSION}

This study demonstrated that child and adolescent psychiatrists tend to regard physical contact with patients as something that should be actively avoided or justified carefully. Previous studies have demonstrated that the general public discriminates carefully between types of touch with children (Harrison-Speake \& Willis, 1995) and that clinicians show a conservative bias in this area (Cowen et al, 1983).

Psychiatry training emphasises the importance of psychological and physical boundaries over ordinary human responses within the therapeutic relationship. Rare incidents of alleged professional misconduct fuel anxiety and support a conservative bias. For professional training and experience to so profoundly influence practice they must be based on sound clinical evidence rather than fear. It is important that reservations about physical contact do not discount research in this area.

In contrast to other branches of medicine, child psychiatry emphasises emotional context, and physical examination and treatment are less central to practice. Given the interrelationship between physical

Table I Levels of physical contact considered appropriate by psychiatrists towards a 6 -year-old child who is distressed or in danger'. Frequency of each response (percentage of total respondents, $n=26 \mathrm{I}$ ).

\begin{tabular}{|c|c|c|c|c|c|c|c|c|}
\hline \multicolumn{4}{|c|}{ Distressed child } & \multicolumn{5}{|c|}{ Child in danger } \\
\hline $\begin{array}{l}\text { Hand on } \\
\text { arm }\end{array}$ & $\begin{array}{l}\text { Arm } \\
\text { around } \\
\text { child }\end{array}$ & $\begin{array}{l}\text { Given } \\
\text { cuddle }\end{array}$ & $\begin{array}{l}\text { Do not } \\
\text { touch }\end{array}$ & $\begin{array}{c}\text { Do } \\
\text { nothing }\end{array}$ & $\begin{array}{l}\text { Call } \\
\text { them }\end{array}$ & $\begin{array}{l}\text { Chase } \\
\text { them }\end{array}$ & $\begin{array}{c}\text { Restrain } \\
\text { them }\end{array}$ & $\begin{array}{c}\text { Ask someone } \\
\text { else to restrain } \\
\text { them }\end{array}$ \\
\hline $182^{2}(70)$ & $48(18)$ & $14(5)$ & $193^{3}(74)$ & $3(I)$ & $143(55)$ & II 8 (45) & $179(69)$ & $93(36)$ \\
\hline
\end{tabular}

I. Respondents could select more than one response.

2. Of these 182 respondents, 162 (62\% of all respondents) reported that it was 'appropriate', and $20(8 \%)$ that it was 'very appropriate' to place a hand on the distressed child's arm.

3. Of these 193 respondents, 174 (67\% of all respondents) reported that it was 'appropriate', and 19 (7\%) that it was 'very appropriate' to not touch a distressed child. and mental disorders in children, rigid avoidance of physical contact might be untenable.

Psychiatrists need to become more confident about evaluating their use of physical contact in a range of clinical settings. Relevant research must be multidisciplinary in nature and take account of the views of carers and children. We hope that this study will provide a first step towards the development of evidence-based guidance concerning this sensitive and complex issue.

\section{ACKNOWLEDGEMENTS}

This study was approved by the University of Glasgow Medical Faculty Research Ethics Committee, and supported by the John Robertson Bequest Fund. Use of the Royal College of Psychiatrists' membership database for the specific purpose of this research was approved by the Registrar of the College. We thank Dr David Young for statistical advice, Drs Ama Addo and David Jones for help with setting up the pilot study, Mrs Irene O'Neill for secretarial support, and to our child and adolescent psychiatric colleagues for their participation.

\section{REFERENCES}

Brody, V. A. (1992) The dialogue of touch developmental play therapy. International Journal of Play Therapy, I, 2I-30.

Cowen, E. L., Weissberg, R. P. \& Lotyczewski, B. S. (1983) Physical contact in interactions between clinicians and young children. Journal of Consulting and Clinical Psychology, 5I, 132-138.

Feldman, R. (2004) Mother-child touch patterns in infant feeding disorders: relation to maternal, child and environmental factors. Journal of the American Academy of Child and Adolescent Psychiatry, 43, 1089-1097.

Field, T. M. (1998) Touch therapy effects on development. International journal of Behavioural Development, 22, 779-797.

Harrison-Speake, K. \& Willis, F. N. (1995) Ratings of the appropriateness of touch among family members. Journal of Nonverbal Behavior, 19, 85-100.

Klein, J. G. (2005) Five pitfalls in decisions about diagnosis and prescribing. BMJ, 330, 78I-783.

Masters, K. J., Bellonci, C. \& the Work Group on Quality Issues (2002) Practice parameter for the prevention and management of aggressive behavior in child and adolescent psychiatric institutions, with special reference to seclusion and restraint. Journal of the American Academy of Child and Adolescent Psychiatry, $\mathbf{4 I}$ (suppl), 4S-24S. 